\title{
Increased dietary protein in the second trimester of gestation increases live weight gain and carcass composition in weaner calves to 6 months of age
}

\author{
G. G. Miguel-Pacheco ${ }^{1}$, L. D. Curtain ${ }^{2}$, C. Rutland ${ }^{1}$, L. Knott ${ }^{3}$, S. T. Norman ${ }^{4}$, N. J. Phillips ${ }^{3}$ \\ and V. E. A. Perry ${ }^{1,5 \dagger}$ \\ ${ }^{1}$ School of Veterinary Medicine and Science, University of Nottingham, Sutton Bonington LE12 5RD, UK; ${ }^{2}$ School of Animal Studies, University of Queensland, Gatton, \\ QLD 4345, Australia; ${ }^{3}$ School of Veterinary Science, University of Queensland, Gatton, QLD 4345, Australia; ${ }^{4}$ School of Animal and Veterinary Sciences, Charles Sturt \\ University, Wagga Wagga, NSW 2650, Australia; ${ }^{5}$ Robinson Research Institute, School of Medicine, University of Adelaide, Frome Road, SA 5001, Australia
}

(Received 14 February 2016; Accepted 29 September 2016; First published online 8 November 2016)

Genetically similar nulliparous Polled Hereford heifers from a closed pedigree herd were used to evaluate the effects of dietary protein during the first and second trimester of gestation upon foetal, placental and postnatal growth. Heifers were randomly allocated into two groups at 35 days after artificial insemination (35 days post conception (dpc)) to a single bull and fed high $(15.7 \%$ CP) or low (5.9\% CP) protein in the first trimester (T1). At 90 dpc, half of each nutritional treatment group changed to a high- or low-protein diet for the second trimester until $180 \mathrm{dpc}$ (T2). High protein intake in the second trimester increased birth weight in females $(\mathrm{P}=0.05)$, but there was no effect of treatment upon birth weight when taken over both sexes. Biparietal diameter was significantly increased by high protein in the second trimester with the effect being greater in the female $(\mathrm{P}=0.02)$, but also significant overall $(\mathrm{P}=0.05)$. Placental weight was positively correlated with birth weight, fibroblast volume and relative blood vessel volume $(\mathrm{P}<0.05)$. Placental fibroblast density was increased and trophoblast volume decreased in the high-protein first trimester treatment group $(\mathrm{P}<0.05)$. There was a trend for placental weight to be increased by high protein in the second trimester $(\mathrm{P}=0.06)$. Calves from heifers fed the high-protein treatment in the second trimester weighed significantly more on all occasions preweaning (at 1 month $(\mathrm{P}=0.0004), 2$ months $(\mathrm{P}=0.006), 3$ months $(\mathrm{P}=0.002), 4$ months $(\mathrm{P}=0.01), 5$ months $(\mathrm{P}=0.03), 6$ months $(\mathrm{P}=0.001))$, and grew at a faster rate over the 6-month period. By 6 months of age, the calves from heifers fed high nutrition in the second trimester weighed $33 \mathrm{~kg}$ heavier than those fed the low diet in the second trimester. These results suggest that dietary protein in early pregnancy alters the development of the bovine placenta and calf growth to weaning.

Keywords: foetal programming, bovine, calf growth, gestation diet

\section{Implications}

Protein supplementation during pregnancy in nulliparous heifers may significantly increase growth rate and muscle development in the progeny. This may have significant financial implications to the cattle producer. This effect may in part be executed via the observed adaptations in the developing placenta.

\section{Introduction}

It is well established from epidemiological studies in human populations and experimental studies in a range of animal

\footnotetext{
${ }^{\dagger}$ E-mail: viv.perry@nottingham.ac.uk
}

models that varying maternal nutrition during critical periods of foetal development can alter or 'program' body mass and body composition in later life (Symonds et al., 2004; Micke et al., 2010a; Micke et al., 2011a; Micke et al., 2011b). Range cattle managed under extensive conditions experience such variations in maternal nutrition sufficient to affect foetal programming and thereby the postnatal growth and carcass characteristics of their progeny (Cafe et al., 2006; Greenwood et al., 2006; Martin et al., 2007; Micke et al., 2010a; Summers et al., 2015). Maternal nutrient supply to the foetus regulates the foetal IGF axis (Oliver et al., 1996; Sullivan et al., 2009a) and can programme the postnatal IGF axis (Micke et al., 2010a; Symonds et al., 2012). Calf plasma IGF-1 at birth is positively associated with birth weight (Breier et al., 1988; Micke et al., 2010a), as is postnatal IGF 
concentration with average daily gain (ADG) and linear growth (Lund-Larsen et al., 1977; Micke et al., 2010a; Micke et al., 2010b). The reported effects of foetal programming upon ADG and carcass development in cattle progeny is however inconsistent (Greenwood et al., 2005; Micke et al., $2011 \mathrm{~b}$; Summers et al., 2015). The disparity recorded between these studies may be influenced by the genetic heterogeneity, and age of the dams observed as well as timing of intervention: the Greenwood et al. (2005) study used both pluriparous and nulliparous dams, whereas the Micke et al. (2011b) and Summers et al. (2015) only nulliparous, with each study using different relatively diverse genotypes and intervention periods.

In this study, nulliparous Polled Hereford heifers from a closed stud herd mated at 15 months of age were used, ensuring a reduction in genetic variation within the dams and enabling focus upon the adolescent yearling heifer which has been shown to be more susceptible to foetal growth restriction following gestational nutritional perturbation (Copping et al., 2014; Hernandez-Medrano et al., 2015). Based on our former studies (Perry et al., 1999; Sullivan et al., 2009b; Micke et al., 2010a; Micke et al., 2015), we hypothesise that low protein in the first trimester will enhance placental development and in the second trimester will result in reduced growth and carcass muscling in the offspring.

\section{Materials and methods}

\section{Project animals management and treatments}

All procedures were performed with the approval of the University of Queensland Animal Ethics Committee, approval number SVS/748/08. Genetically similar Polled Hereford heifers $(n=80), \sim 15$ months old from the same closed pedigree herd, were selected for inclusion in this trial. Preceding artificial insemination, the heifers were weighed and their reproductive tract palpated for normality. Oestrus was synchronised by insertion of intravaginal progesterone implants ('EAZI-BREED CIDR-B'; Genetics Australia, Bacchus Marsh, VIC, Australia) for 11 days, with an injection of $12.5 \mathrm{mg}$ of dinoprost tromethamine (Lutalyse; Upjohn Pty Limited, Rydalmere, NSW, Australia) and $500 \mathrm{IU}$ of equine chorionic gonadotrophin (ECG) on the day of CIDR removal. Approximately $48 \mathrm{~h}$ after the CIDR implants were removed, the heifers were all artificially inseminated on the same day without detection of oestrus. The sire used was a Polled Hereford bull with an estimated breeding value for birth weight of $+2.1 \mathrm{~kg}$ at $86 \%$ reliability.

The study design was a $2 \times 2$ factorial design. The heifers were stratified by body weight and randomly allocated to two equal first trimester (T1) dietary treatment groups, high $(15.7 \%$ CP) and low (5.9\% CP) protein at 14 days post conception (dpc). Pregnancy diagnosis was completed by manual palpation at 35 days following insemination (taken as $35 \mathrm{dpc}$ ). As T1 treatment did not start at conception, the periconception period is, therefore, not addressed. After pregnancy diagnosis, all non-pregnant animals were removed from trial $(n=21)$. Following an outbreak of
Bovine Ephemeral Fever during trimester 1, 17 heifers were recorded to have aborted and were excluded from the study. The remaining numbers of calves in each treatment period were: T1 high protein, $n=10$ consisting of six male and four female calves; and T1 Low protein, $n=11$ consisting of seven male and four female. At $90 \mathrm{dpc}$ half of each nutritional group was changed to a high $(15.6 \% \mathrm{CP})$ or low $(6.1 \% \mathrm{CP})$ protein treatment until $180 \mathrm{dpc}$ (T2). Numbers of animals in T2 high protein: $n=13$ consisting of 10 male and three female; and in T2 low protein: $n=8$ consisting of three male and five female. This factorial design gave rise to four treatment groups: high/high ( $\mathrm{HH}$; four males and two female), high/low ( $\mathrm{HL}$; two males and two females), low/high ( $\mathrm{LH}$; six males and one female), low/low (LL; one male and three females). After $180 \mathrm{dpc}$ heifers were run together on the same native pasture during the final trimester until term. The diet for this final trimester consisted of native pasture, containing grasses and medicago polymorpha with a CP value ranging between $10 \%$ and $13 \%$ over the trimester. Both dietary groups of heifers received a grain ration and either ad libitum pasture hay (low) or pasture grazing (high). Details on dry matter intake (DMI) calculations are given in (Table 1).

Before calving, heifers were individually placed in a small yard. Measurements were taken of the newborn calf before suckling (birth weight (BIRW) and biparietal diameter (BPD)), and the foetal portion of the placenta was collected

Table 1 Nutrient content of dietary rations fed to dams during each trimester of gestation ( $T 1=36$ to $90 \mathrm{dpc}, T 2=90$ to $180 \mathrm{dpc}$ or $T 3=181$ to term) by treatment (high or low)

\begin{tabular}{|c|c|c|c|c|c|}
\hline \multirow[b]{3}{*}{ Feed sources } & \multicolumn{2}{|c|}{$\mathrm{T} 1$} & \multicolumn{2}{|c|}{$\mathrm{T} 2$} & \multirow{2}{*}{$\frac{\mathrm{T} 3}{181 \text { to term }}$} \\
\hline & \multicolumn{2}{|c|}{ (36 to 90 ) } & \multicolumn{2}{|c|}{ (90 to 180 ) } & \\
\hline & High & Low & High & Low & All cows \\
\hline Hay (kg) & - & 3.74 & - & 4.00 & - \\
\hline Pasture (kg) & 5.72 & - & 6.00 & - & 7.20 \\
\hline Sorghum (kg) & - & 2.61 & - & 2.61 & - \\
\hline Copra meal (kg) & 1.80 & - & 1.80 & - & - \\
\hline Calcium $(\mathrm{g} / \mathrm{kg}$ ) & 1.10 & 2.60 & 1.10 & 2.60 & 1.10 \\
\hline Phosphorus (g/kg) & 9.20 & 5.20 & 9.20 & 5.20 & 9.20 \\
\hline DMI total $^{1}$ & 7.52 & 6.35 & 7.80 & 6.61 & 7.20 \\
\hline Energy intake (MJ) & 70.50 & 57.50 & 72.20 & 64.00 & 63.40 \\
\hline Energy $\left(\% \mathrm{NRC}^{2}\right)$ & 100.00 & 90.00 & 103.00 & 92.00 & 101.00 \\
\hline $\mathrm{CP}(\mathrm{kg})$ & 1.18 & 0.38 & 1.22 & 0.40 & 0.99 \\
\hline CP $(\%)$ & 15.70 & 5.98 & 15.64 & 6.05 & 13.70 \\
\hline CP (\%NRC) & 174.00 & 66.00 & 179.00 & 70.00 & 125.00 \\
\hline
\end{tabular}

Data are presented on an as-fed dry matter (DM) basis per heifer per day. ${ }^{1}$ Estimates of DMI from pasture and hay were calculated based upon the National Research Council (NRC) energy requirements for replacement Bos taurus pregnant heifers with a mature weight of $500 \mathrm{~kg}$ and a calf birth weight of $32 \mathrm{~kg}$. As the sorghum and copra meal energy content were known (12 and $11.2 \mathrm{MJ} / \mathrm{kg} \mathrm{DM}$, respectively) and the heifers on the low-protein diet averaged $340 \mathrm{~kg}$ with a rate of gain of $0.8 \mathrm{~kg}$ during the first trimester, the DMI of pasture and hay was calculated based upon the energy requirement sufficient to sustain this rate of gain. Similar DMI estimations were completed in the second and third trimesters based on the rate of gain in each treatment group. ${ }^{2} \mathrm{NRC}$ comparison to ration to NRC (1996) recommended nutrient requirements for pregnant yearling Bos taurus replacement heifers with calf weight of $32 \mathrm{~kg}$. 
immediately upon expulsion. Placental measures included wet weight, cotyledon number and wet weight of cotyledons (CWW) post separation from adjoining membranes. The dry cotyledon weight (CDW) measure was obtained by drying cotyledons overnight at $100^{\circ} \mathrm{C}$ and then weighing at $1 \mathrm{~h}$ intervals, until the same weight was recorded on three consecutive weightings.

After calving, all the heifers were grazed together with their calves on native pasture. Weights from the heifers and calves were recorded monthly. At 6 months of age, ultrasound (model Aloka-500 ${ }^{\circledR}$; Aloka Inc., Tokyo, Japan with $3 \mathrm{MHz}$ linear probe) was used to assess fat depth at the P8 (rump) and 12th rib (FT12) sites (Hopkins, 1989). Anal Fat Fold (AFFT), the thickness of skin and subcutaneous fat situated between the point of the ischium and the base of the tail, was assessed using techniques described by Johnson (1994) by a single experienced technician using calibrated calipers. Heifers were fasted for $6 \mathrm{~h}$ and weighed to obtain their empty live weight (ELW). ELW and AFFT were used to calculate the percentage carcass components (muscle, fat and bone) following the published regression equations in Bos taurus Hereford cattle by Johnson (1994).

\section{Quantitative analysis of placental tissue}

The placenta was immediately collected after expulsion (Stage 3 of labour varying between 0.5 and $6 \mathrm{~h}$ ) at term and weighed whole before excision of all cotyledons from the surrounding membranes (Perry et al., 1999). Those not completely expelled by $6 \mathrm{~h}$ post calving were considered retained foetal membranes and not used. One small (average $4.4 \mathrm{~g}$ ), one medium (average $24.2 \mathrm{~g}$ ) and one large cotyledon (average $55 \mathrm{~g}$ ) were removed from the gravid horn, fixed in neutral buffered formalin (10\%) for $48 \mathrm{~h}$, processed and embedded in paraffin wax. Two-micron sections were cut from each cotyledon and stained with haematoxylin-eosin (H\&E) with a further section stained with Masson's Trichrome.

Quantitative analysis was used to calculate volume densities and relative total component volumes of major cellular components, surface density and barrier thickness of trophectoderm. An L-36 Merz grid was used in conjunction with a video image analysis system as detailed by Perry et al. (1999) for morphometric analysis, at a final magnification of $250 \times$ (Nikon 80i microscope with Nikon DS camera system software; Nikon, Tokyo, Japan). The points falling on each structure or component were manually assigned using morphological features appropriate to H\&E or Masson's Trichrome as appropriate, blood vessels were not differentiated between arteries, veins or capillaries. Ten systematic random fields of each cotyledon, of each size, were analysed (three cotyledons per cow), thus 30 fields were analysed per animal to calculate structural quantities (Weibel et al., 1966). The cellular components that were measured and counted by point and intersection counting were: trophectoderm, connective tissue matrix, connective tissue fibroblasts and connective tissue blood vessels.
Equations detailed by Weibel et al. (1966), were used to calculate relative volume densities of each component, surface density and mean barrier thickness of the foetal trophectoderm. The relative volume densities (calculated at $1 \mathrm{~g}$ of placenta occupying $1 \mathrm{~cm}^{3}$ ) in conjunction with the CWW (collected as detailed above) of each placenta were used to calculate relative total component volumes of cellular components. The surface area of the foetal trophectoderm was also calculated from the number of times the lines on the Merz grid intersected the surface of the trophectoderm. Volume density $=$ number of points falling on structure/total number of test points $\left(V_{d}=P_{a} / P_{T}\right)$. Relative volume of each component $=$ volume density $X$ placental weight in grams $\left(V_{c}=V_{d} \times\right.$ weight $\left.(\mathrm{g})\right)$. Surface density $=2 \times$ number of intercepts/total length of lines $\left(S_{V}=2 \times L_{d} / L_{T}\right)$. Barrier thickness $=$ trophoblast volume density/surface density of the trophoblast $\left(B_{T}=D_{d} / S_{v}\right)$ (Weibel et al., 1966; Roberts et al., 2001). Every photomicrograph was high quality and could be counted, resulting in 1080 point counts per animal.

\section{Statistical analyses}

The study used a $2 \times 2$ factorial design, with factors being nutrition in the first trimester ( $\mathrm{T} 1$ ) and the second trimester (T2). Statistical analyses were performed using StataCorp. 2015 (Stata Statistical Software: Release 14; StataCorp LP, College Station, TX, USA), and significance was set at $P<0.05$ for all the results. Normality and equality of variance was checked before any analysis and transformation of the data was applied if it was necessary.

Birth calf weights were analysed using ANOVA with $\mathrm{T} 1 \times \mathrm{T} 2$, with sex used as covariate. Birth weight and the monthly calf weights were all subjected to ANOVA with repeated measures, and sex and calf age were added as covariates. For each calf the ADG ( $\mathrm{kg} /$ day) between birth and the final weighing was computed. This calculation involved just the first and last set of weights. The linear growth rate (g/day), which involved fitting a straight line to the weight data and estimating the slope, was also calculated yielding the linear growth rate. Both calculations gave very similar results with live weights and growth rates showing the same response to the treatments.

Muscle, fat and bone in the live animal were considered as three separate dependent variables, against the fixed effects of nutrition in $\mathrm{T} 1 \times \mathrm{T} 2$ and sex. The effect of group was also analysed. ANOVA was used to examine treatment effects upon placental tissues adding calf sex as covariate. Correlation coefficients between treatment effects and other parameters were also calculated using Pearson's correlation coefficient and were also considered statistically significant if $P<0.05$.

\section{Results}

Placental gross morphometry

There was a trend for placental weight to be increased in the high-protein second trimester treatment group $(P=0.06)$, 
Miguel-Pacheco, Curtain, Rutland, Knott, Norman, Phillips and Perry

Table 2 Placental gross morphometry and calf measurements at birth by treatment group

\begin{tabular}{|c|c|c|c|c|c|c|c|c|}
\hline \multirow{3}{*}{$\begin{array}{l}\text { First trimester } \\
\text { Second trimester }\end{array}$} & \multicolumn{4}{|c|}{ High protein } & \multicolumn{4}{|c|}{ Low protein } \\
\hline & \multicolumn{2}{|c|}{ High } & \multicolumn{2}{|c|}{ Low } & \multicolumn{2}{|c|}{ High } & \multicolumn{2}{|c|}{ Low } \\
\hline & Mean & SEM & Mean & SEM & Mean & SEM & Mean & SEM \\
\hline \multicolumn{9}{|l|}{ Placental gross morphometry } \\
\hline Number of cotyledons & 78.0 & \pm 6.9 & 98.5 & \pm 18.5 & 78.5 & \pm 7.3 & 70.3 & \pm 8.2 \\
\hline Cotyledon wet weight $(\mathrm{g})$ & 1493.3 & \pm 82.7 & 1308.5 & \pm 91.5 & 1544.3 & \pm 165.7 & 1335.0 & \pm 163.5 \\
\hline Cotyledon dry weight (g) & 124.3 & \pm 17.1 & 88.8 & \pm 22.7 & 128.4 & \pm 20.5 & 130.6 & \pm 12.4 \\
\hline Placental wet weight $(\mathrm{g})^{1}$ & 4923.8 & \pm 356.5 & 3935.0 & \pm 585.0 & 4247.0 & \pm 367.9 & 3405.5 & \pm 561.2 \\
\hline \multicolumn{9}{|l|}{ Calves measurements } \\
\hline Birth weight & 36.8 & \pm 0.9 & 31.0 & \pm 1.8 & 36.7 & \pm 2.3 & 36.0 & \pm 1.9 \\
\hline BPD & $10.8^{\mathrm{b}}$ & \pm 0.1 & $10.5^{\mathrm{a}}$ & \pm 0.2 & $10.7^{b}$ & \pm 0.2 & $10.3^{\mathrm{a}}$ & \pm 0.2 \\
\hline
\end{tabular}

$\mathrm{BPD}=$ biparietal diameter.

${ }^{\mathrm{a}, \mathrm{b}}$ Different alphabetic superscripts denote mean values which are significantly different from each other $(P<0.05)$.

${ }^{1}$ The observed increase in placental weight by second trimester high-protein treatment was below this level at $P=0.06$.

Table 3 Cellular composition of bovine placenta by treatment group

\begin{tabular}{|c|c|c|c|c|c|c|c|c|}
\hline \multirow{3}{*}{$\frac{\text { First trimester }}{\text { Second trimester }}$} & \multicolumn{4}{|c|}{ High protein } & \multicolumn{4}{|c|}{ Low protein } \\
\hline & \multicolumn{2}{|c|}{ High } & \multicolumn{2}{|c|}{ Low } & \multicolumn{2}{|c|}{ High } & \multicolumn{2}{|c|}{ Low } \\
\hline & Mean & SEM & Mean & SEM & Mean & SEM & Mean & SEM \\
\hline \multicolumn{9}{|l|}{ Cellular composition of bovine placenta } \\
\hline Surface density of trophectoderm $\left(\mathrm{cm}^{-1}\right)$ & 202.8 & \pm 7.5 & 205.1 & \pm 17.4 & 202.5 & \pm 15.06 & 210.4 & \pm 25.5 \\
\hline Barrier thickness of trophectoderm $(\mathrm{cm})$ & 0.233 & \pm 0.015 & 0.247 & \pm 0.014 & 0.237 & \pm 0.015 & 0.262 & \pm 0.042 \\
\hline \multicolumn{9}{|l|}{ Volume densities $\left(\mathrm{cm}^{0}\right)$} \\
\hline Trophectoderm & 0.485 & \pm 0.026 & 0.511 & \pm 0.029 & 0.473 & \pm 0.027 & 0.526 & \pm 0.023 \\
\hline Matrix & 0.398 & \pm 0.021 & 0.381 & \pm 0.012 & 0.358 & \pm 0.042 & 0.381 & \pm 0.031 \\
\hline Fibroblast & $0.038^{a}$ & \pm 0.004 & $0.035^{\mathrm{a}}$ & \pm 0.002 & $0.031^{b}$ & \pm 0.002 & $0.025^{b}$ & \pm 0.004 \\
\hline Blood vessel volume density & 0.092 & \pm 0.015 & 0.087 & \pm 0.023 & 0.091 & \pm 0.009 & 0.066 & \pm 0.016 \\
\hline \multicolumn{9}{|l|}{ Relative volume of each component $\left(\mathrm{cm}^{3}\right)$} \\
\hline Trophectoderm volume & $653.9^{\mathrm{a}}$ & \pm 73.4 & $636.6^{\mathrm{a}}$ & \pm 7.4 & $723.5^{\mathrm{b}}$ & \pm 68.6 & $709.02^{b}$ & \pm 112.9 \\
\hline Matrix volume & 597.7 & \pm 52.6 & 484.2 & \pm 43.6 & 574.0 & \pm 106.4 & 497.3 & \pm 41.57 \\
\hline Fibroblast volume & 57.04 & \pm 7.69 & 48.41 & \pm 3.38 & 47.61 & \pm 6.37 & 32.05 & \pm 5.64 \\
\hline Blood vessel volume & 141.3 & \pm 26.9 & 141.3 & \pm 37.9 & 146.6 & \pm 31.3 & 95.3 & \pm 32.2 \\
\hline
\end{tabular}

Values are unadjusted mean and $\pm \mathrm{SEM}$ of the cellular composition of bovine placenta by treatment group. Volume densities are a proportion, dimensionless numbers as they are a ratio of two numbers $=\mathrm{cm}^{0}$; Surface density measures surface area per volume or weight of tissue $\left(\mathrm{g}\right.$ of cotyledon) $\left(\mathrm{cm}^{2} / \mathrm{cm}^{3}\right)=\mathrm{cm}^{-1}$; Barrier thickness of trophectoderm - linear measurement $=\mathrm{cm}$; relative volume of each component assumes $1 \mathrm{~g}$ of placenta occupies $1 \mathrm{~cm}^{3}=\mathrm{cm}^{3}$.

${ }^{a, b}$ Different alphabetic superscripts denote mean values that are significantly different $(P<0.05)$ from each other.

but there was no significant effect upon CWW and CDW. In addition, no significant differences were observed between treatments in relation to cotyledon number (Table 2).

\section{Placental cellular components}

Fibroblast density was increased by the high-protein treatment in the first trimester $(P=0.01$; Table 3$)$, whereas low protein intake in the first trimester increased trophectoderm volume $(P<0.05$; Table 3$)$. There were, however, no significant effects of treatment upon other density measures of cellular components, matrix density and relative blood vessel volume density (BVVD). There were no statistically significant interactions between treatments for any of the cellular components measured (Table 3).

\section{Calf measures at birth}

High protein in the second trimester significantly increased BPD $(P=0.05$; Table 2$)$, with a greater effect in female progeny $(P=0.02)$. There was a similar effect of second trimester high-protein diet increasing birth weight in female progeny $(P=0.05)$, however no effect of treatment on overall birth weight. There was no interaction between treatment and sex. There was increased variability in the birth weight of male calves.

\section{Relationships between birth weight and placental parameters}

BIRW was positively correlated with placental weight, CWW, and cotyledon number, with a tendency for a positively 
Table 4 Correlation coefficients (r) between birth weight and placental parameters

\begin{tabular}{lcc}
\hline \hline Variables & $r$ & $P$ \\
\hline Placental parameters & & \\
Placental weight & 0.52 & 0.03 \\
CWW & 0.65 & 0.003 \\
CDW & 0.43 & 0.07 \\
Cotyledon number & 0.46 & 0.05 \\
Cellular placental parameters & & \\
Trophectoderm relative volume & 0.392 & $\mathrm{Ns}$ \\
Matrix relative volume & 0.601 & 0.008 \\
Fibroblast relative volume & 0.331 & $\mathrm{Ns}$ \\
Blood vessel relative volume & 0.518 & 0.03 \\
Trophectoderm volume density & -0.242 & $\mathrm{Ns}$ \\
Matrix volume density & 0.249 & $\mathrm{Ns}$ \\
Fibroblast volume density & -0.022 & $\mathrm{Ns}$ \\
Blood vessel volume density & 0.439 & 0.06 \\
Surface density of the trophectoderm & -0.396 & $\mathrm{Ns}$ \\
Barrier thickness of trophectoderm & 0.114 & $\mathrm{Ns}$ \\
\hline \hline
\end{tabular}

CWW = cotyledon wet weight; CDW = cotyledon dry weight; Ns = not significant.

correlation with $\mathrm{CDW}$. The strongest correlation being with CWW $(r=0.65, P=0.003$; Table 4). Relative matrix volume $(P=0.008)$ and relative blood vessel volume (BVV) $(P=0.03)$ were the only cellular parameters correlated with BIRW (Table 4). Cotyledon number was highly positively correlated with BVVD $(r=0.569, P=0.014)$, matrix volume $(r=0.497, \quad P=0.036)$, fibroblast volume $(r=0.594$, $P=0.009), \quad$ BVV $(r=0.575, \quad P=0.012)$ and CWW $(r=0.531, P=0.023)$; and negatively correlated with surface density $(r=-0.605, P=0.008)$ and trophectoderm volume density $(r=-0.493, P=0.037)$. BPD had strong positive correlations with $\operatorname{BVVD}(r=0.674, P=0.002)$, matrix volume $(r=0.685, P=0.002)$, BVV $(r=0.769$, $P=0.0002), \quad$ BIRW $\quad(r=0.678, \quad P=0.001), \quad$ CWW $(r=0.783, P=0.0001), \operatorname{CDW}(r=0.511, P=0.03)$ and placental weight $(r=0.679, P=0.001)$. Placental weight was significantly positively correlated with matrix volume $(r=0.653, \quad P=0.003)$, fibroblast volume $(r=0.498$, $P=0.035), \quad$ BVV $\quad(r=0.522, \quad P=0.03) \quad$ and $\quad$ BVVD $(r=0.478, P=0.04)$.

\section{Preweaning growth of calves}

Calf live weights and growth rates showed a similar response to the treatments, whereby there was no effect of nutrition in trimester one on $A D G$, and there was no sex effect observed on ADG and no interaction between protein levels fed in trimesters one and two $(P>0.05)$. There was a significant effect of nutrition in trimester 2 on ADG $(P=0.01)$ (Figure 1). Calves from heifers fed the high-protein diet in the second trimester weighed significantly more on all occasions (at 1 month $(P=0.004), 2$ months $(P=0.006), 3$ months $(P=0.002), 4$ months $(P=0.01), 5$ months $(P=0.03)$, 6 months $(P=0.01)$, and grew at a faster rate over the 6 -month period (Figure 1). By 6 months of age, the calves from the heifers fed the high-protein diet in the second

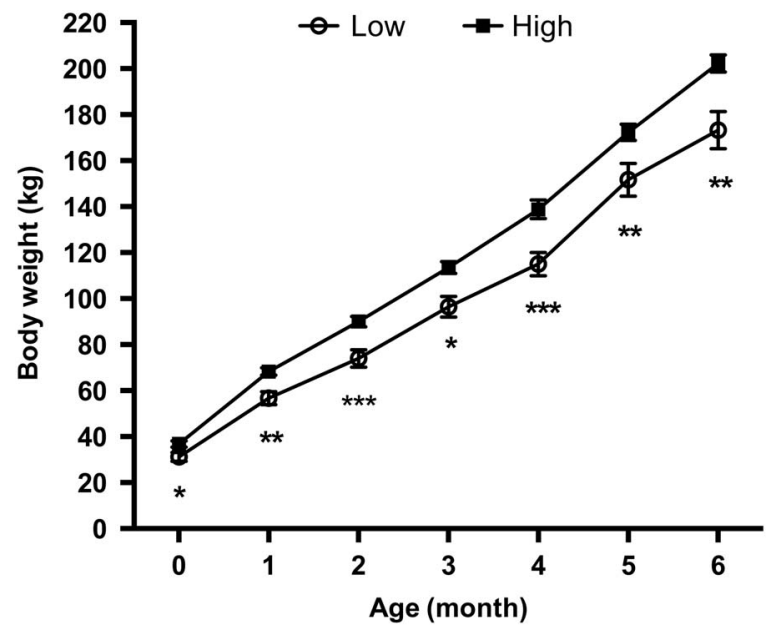

Figure 1 Mean and \pm SEM of calf body weight from birth (0 months) until 6 months of age by treatment during the second trimester. Levels of significance indicated by ${ }^{*} P<0.05,{ }^{* *} P<0.01$ and ${ }^{* * *} P<0.001$, respectively.

trimester weighed $33 \mathrm{~kg}$ heavier than those fed the low diet in the second trimester ( $16 \%$ heavier).

In the live carcass measures, there was a sex effect on the amount of muscle $(P=0.0001)$ and fat $(P=0.0007)$, but not bone $(P=0.91)$; males had increased muscle $(59.67 \pm 0.26)$ and less fat $(23.15 \pm 0.38)$ compared with females (muscle: $57.04 \pm 0.51$, and fat: $26.71 \pm 0.76$ ). For all three variables, there was a significant effect of nutrition in trimester 1 and a significant interaction between nutrition fed in the two trimesters. Decreased protein during trimester 1 led to increased muscle $(P=0.002)$ and decreased fat $(P=0.002)$. Animals in the $\mathrm{HL}$ group had significantly lower muscle and bone percentages and significantly higher fat percentages than animals in the LL group. No other group was different from another in either muscle bone or fat (Table 5).

\section{Discussion}

This study provides clear evidence that nutrition during the first two trimesters of pregnancy alters the growth and body phenotype of the calf. Importantly, decreasing genetic variability in the heifer dams enabled this clear effect of gestational protein manipulation upon progeny growth to be revealed. The analysis of weight gain of progeny supports the hypothesis that providing heifers with a high-protein diet in the second trimester resulted in a faster growth rate and a significant increase in body weight $(\sim 33 \mathrm{~kg})$ in their calves at 6 months of age when compared with calves born to heifers fed low protein in the second trimester. Further, this study also shows early gestational dietary protein affects the developing placenta and supports the hypothesis that reduced protein in the first trimester increases physiologically important components of placental development. These findings are of significant interest to the cattle industry in 
Australia as protein is the most deficient nutrient in the Australian rangelands (Norman, 1963; Sullivan et al., 2009a).

This downside to utilising these high-value pedigree animals and the farm site of this study was a reduction in the level of intervention permitted. This included prevention of dietary intervention before $35 \mathrm{dpc}$, which is known to affect foetal development (Copping et al., 2014; HernandezMedrano et al., 2015).

Poor maternal dietary protein in early gestation has been shown to impair bovine foetal growth (Long et al., 2009; Micke et al., 2010b; Copping et al., 2014), which was confirmed in this experiment. Low dietary protein intake in the second trimester decreased BPD similar to previous experiments although birth weight was not affected as comprehensively as previously reported (Cafe et al., 2006; Micke et al., 2010c), being only significant in the female. The relatively small numbers in this experiment compared with the Micke paper (Micke et al., 2010c) may have influenced this result as variability was greater in the male calves. Furthermore, birth weight at term may not be indicative of intrauterine growth restriction (IUGR) in earlier gestation (Long et al., 2009; Hernandez-Medrano et al., 2015) in the bovine. BPD and BIRW had a strong positive relationship with placental weight and the placental parameters of BVV, CWW and CDW, concomitant with previous studies (Perry et al., 1999; Sullivan et al., 2009b). There was a trend $(P=0.06)$ for placental weight to be increased by increased dietary protein in the second trimester, whereas trophectoderm volume was increased by high-protein first trimester as previously described (Perry et al., 1999). The initial rapid growth of the placenta has been linked to the rapid and vigorous development of the foetal trophoblast through proliferation and branching of the foetal villi into the maternal stromal tissue (Bell et al., 1999). Interdigitation between the foetal trophectoderm and maternal microvilli is complete by $28 \mathrm{dpc}$ in the bovine (Wooding and Beckers, 1987), which is before the initiation of our dietary treatments. Placentome weight and surface area in the bovine however, continually increase until term unlike the ovine in which placentome weight is constant or decreasing from $65 \mathrm{dpc}$ (Baur, 1977; Reynolds and Redmer, 1995). The observed increase in trophectoderm volume in the lowprotein heifers during the first trimester may enhance the functional potential of the placenta during this period of maximal villi development and thereby enable an increased nutrient supply to the foetus during later gestation if protein availability increases. Supporting evidence suggesting that the protein restricted bovine foetus signals to the placenta an increased requirement for nutrients is found in its ability to increase blood supply via the uterine artery (HernandezMedrano et al., 2015) and increased cotyledonary vasculature (Zhu et al., 2007) at $125 \mathrm{dpc}$.

The relative vasculature proportions in the foetal cotyledons were not altered in this study, although there was a positive correlation between calf birth weight and vasculature. The literature shows that vascular components 
of the placenta vary greatly depending upon environmental perturbations, dam age, the timing of perturbation and timing of cotyledon excision. Gestational undernutrition (Vonnahme et al., 2007) found decreased bovine cotyledonary vasculature in the later, but not early stages of placental development, whereas Zhu et al. (2007) showed nutrient restriction increased cotyledonary vascularity at day 125 with no affect at day 250. Furthermore, cows in their third or greater pregnancy did not show effects upon placental composition observed in younger heifers (Long et al., 2009). This may illustrate a window and age-specific effect of nutrition upon placental vascularisation.

Connective tissue fibroblast density was increased $(P<0.05)$ in the placenta of heifers receiving the highprotein dietary treatment in the first trimester $(\mathrm{HH}, \mathrm{HL}) \mathrm{a}$ similar finding to that of a previous study by Roberts et al. (2001) in sheep, where maternal dietary restriction $(70 \%$ of recommended intake) reduced the total placental surface area for exchange, and the surface density of trophoblast. However, the arithmetic mean barrier thickness for diffusion in this study was increased by this maternal food restriction (Roberts et al., 2001). Similarly, in the current study barrier thickness of the trophectoderm was increased by protein restriction. It has been suggested by Perry et al. (1999) that a restriction in protein in the first trimester in heifers may lead to a larger placenta at term due to the greater development of the microvilli, particularly if this early period of restriction is followed up by a phase of improved nutrition. Indeed the LH group did have the largest CWW (Table 2), but this was only significantly greater than CWW in the $\mathrm{HH}$ group $(P=0.03)$. It has been suggested (Talbot et al., 2000; Shimada et al., 2001; Dunlap et al., 2006) that trophoblasts from ungulates (including cattle), proliferate in the absence of fibroblast growth factors (FGFs), suggesting that the role of FGFs is more limited in maintaining the trophoblast lineage in cattle in comparison with rodents. It has also been shown that fibroblasts and FGFs play a role in angiogenesis, including within the placenta (Klagsbrun and D'Amore, 1991), therefore a concomitant increase in vasculature within these placentae may be expected.

These results suggest that maternal diet restriction affects the structure and function of the placenta as previously reported (Perry et al., 1999; Long et al., 2009; Sullivan et al., 2009b; Sullivan et al., 2009c). Such perturbations to placental development may reduce foetal growth due to decreased nutrient transport via the placenta (Sullivan et al., 2009c) generating a decrease in birth weight (Perry et al., 1999; Micke et al., 2010c), or alternatively dichotomous placental development (as in the LH group) may be attendant to increased birth weight and associated dystocia.

Interpretation of the carcass composition results requires consideration of the stages of foetal bovine muscle development, which are predominantly controlled by IGF-2 expression that peaks between 150 and $160 \mathrm{dpc}$ (Gerrard and Grant, 1994; Florini et al., 1996). The first wave of differentiation however occurs much earlier when primary skeletal muscle fibres (type I) differentiate from primary myotubes at $39 \mathrm{dpc}$ (Robelin et al., 1993), the second at $90 \mathrm{dpc}$ results in secondary fibres; and a third at $110 \mathrm{dpc}$ gives rise to tertiary fibres (Gagniere et al., 1999). These critical events occur during the dietary treatments imposed in this study.

As myocytes are formed from a pool of pluripotent stem cells (Oksbjerg et al., 2004) extrauterine signals such as those regulated by maternal nutrient intake, may affect the number of cells committed to myoblast formation whilst also affecting the rate of myoblast proliferation and thus final myofibre number. It has previously been reported that gestational dietary regimens effectively alter placental signalling hormones (Sullivan et al., 2009c; Summers et al., 2015). These may act to signal foetal skeletal muscle IGF messenger RNA (mRNA) expression and fibre development during the first two trimesters of gestation as previously shown in foetal skeletal sheep muscle where nutritional restriction increased IGF-2 mRNA expression (Brameld et al., 2000) and increased IGF receptor activity (Symonds et al., 2012). Myofibre density is also reduced by maternal nutrient restriction (Costello et al., 2008). As primary fibres provide the scaffolding for secondary fibre formation, a reduction of primary fibre density resulting from decreased maternal nutrient intake during the first trimester may not be fully compensated for by the provision of increased maternal nutrient intake during the latter stages of gestation. In support of this (Micke et al., 2011b), found that the majority of effects of maternal protein intake upon IGF mRNA expression in adult progeny skeletal muscle occurred during the first trimester of gestation suggesting these early stages of foetal development to be the most sensitive to altered nutritional environment. This is attributed to the high rate of cellular differentiation and proliferation during the early stages of gestation compared with the high rate of cellular hypertrophy during the latter stages (Brameld et al., 2000; Tong et al., 2009). This study is a corollary of previous findings (Micke et al., 2011b) as decreased protein during trimester 1 (LL and $\mathrm{LH}$ combined) increased muscle $(P=0.002)$ and decreased fat $(P=0.002)$ in progeny compared with those animals whose dams received high protein during this period. Though, the predicted values for carcass components presented in this paper are representative of the data presented in Johnson (1994), it is necessary to acknowledge that these predicted measurements may be limited in their inference and accuracy when compared with 'real' carcass measures taken at slaughter.

The treatment effects upon carcass muscle and fat in this study reflect the reciprocal relationship between the development of muscle and adipose tissue, previously reported (Micke et al., 2010a) whereby the in utero diet alters differentiation of the mutual precursor cells of adipocytes and myocytes (Symonds et al., 2012). Furthermore, Micke et al. (2011a) also indicated a possible causal mechanism via the effect of maternal diet upon adipogenic gene expression. The exposure of the developing calf foetus to a high maternal protein intake during the first trimester may result in a relative increase in myostatin gene expression in skeletal muscle as in other species (Liu et al., 2011) and 
this may result in a decrease in muscle fibre number and an increase in the commitment of stem cells within the muscle to form preadipocytes. This effect may, however, be offset in part by an upregulation of the expression of IGF-1 receptor (IGF-1R) as discussed above which occurs in the progeny of such heifers (Micke et al., 2011b).

In this study the lowest muscling occurred in the HL group $(P=0.05)$. As the secondary muscle fibres are the largest contributor to postnatal muscle mass of cattle and begin to form at $90 \mathrm{dpc}$ (Robelin et al., 1993) nutrient restriction during the second trimester may have decreased formation of secondary muscle fibres during myoblast proliferation as reported in sheep (Quigley et al., 2005). Importantly, however, both circulating maternal and progeny IGF-1 has been shown to increase following gestational high dietary protein (Perry et al., 2002; Sullivan et al., 2009a; Micke et al., 2010a). This combined effect in the progeny that experienced increased protein in utero during the second trimester may have produced the increased growth rates observed.

\section{Acknowledgements}

The authors are indebted to the Doyle Family for the use of stud animals and feedstuffs in this experiment to Professor Ray Johnson (Deceased) for the completion of the work on live carcass analysis. G.G.M.-P. was funded by an AHDB grant.

\section{References}

Baur R 1977. Morphometry of the placental exchange areas. Advances in Anatomy Embryology and Cell Biology 53, 1-20.

Bell AW, Hay W and Ehrhardt RA 1999. Placental transport of nutrients and its implications for fetal growth. Journal of Reproduction and Fertility 54, 401-410. Brameld JM, Mostyn A, Dandrea J, Stephenson TJ, Dawson JM, Buttery PJ and Symonds ME 2000. Maternal nutrition alters the expression of insulin-like growth factors in fetal sheep liver and skeletal muscle. Journal of Endocrinology 167, 429-437.

Breier BH, Gluckman PD and Bass JJ 1988. Plasma concentrations of insulin-like growth factor-I and insulin in the infant calf: ontogeny and influence of altered nutrition. Journal of Endocrinology 119, 43-50.

Cafe LM, Hennessy DW, Hearnshaw H, Morris ST and Greenwood PL 2006. Influences of nutrition during pregnancy and lactation on birthweights and growth to weaning of calves sired by Piedmontese and Wagyu bulls. Australian Journal of Experimental Agriculture 46, 245-255.

Copping KJ, Hoare A, Callaghan M, McMillen IC, Rodgers RJ and Perry VEA 2014. Fetal programming in 2-year-old calving heifers: peri-conception and first trimester protein restriction alters fetal growth in a gender-specific manner. Animal Production Science 54, 1333-1337.

Costello PM, Rowelerson A, Astaman NA, Anthony FEW, Sayer AA, Cooper C, Hanson MA and Green LR 2008. Peri-implantation and late gestation maternal undernutrition differentially affect fetal sheep skeletal muscle development. Journal of Physiology 586, 2371-2379.

Dunlap KA, Palmarini M, Varela M, Burghardt RC, Hayashi K, Farmer JL and Spencer TE 2006. Endogenous retroviruses regulate periimplantation placental growth and differentiation. Proc Natl Acad Sci USA 103, 14390-14395.

Florini JR, Ewton DZ and Coolican SA 1996. Growth hormone and the insulin-like growth factor system in myogenesis. Endocrine Reviews 17, 481-517.

Gagniere H, Picard B and Geay Y 1999. Contractile differentiation of foetal cattle muscles: intermuscular variability. Reproduction, Nutrition and Development 39, 637-655.

Gerrard DE and Grant AL 1994. Insulin-like growth factor-II expression in developing skeletal muscle of double muscled and normal cattle. Domestic Animal Endocrinology 11, 339-347.
Greenwood PL, Cafe LM, Hearnshaw H and Hennessy DW 2005. Consequences of nutrition and growth retardation early in life for growth and composition of cattle and eating quality of beef. Recent Advances in Animal Nutrition in Australia 15, 183-195.

Greenwood PL, Cafe LM, Hearnshaw H, Hennessy DW and Morris ST 2006. Long-term consequences of birth weight and growth to weaning on carcass, yield and beef quality characteristics of Peidmontese- and Wagyu-sired cattle. Australian Journal of Experimental Agriculture 46, 257-269.

Hernandez-Medrano JH, Copping KJ, Hoare A, Wapanaar W, Grivell R, Kuchel T, Miguel-Pacheco G, McMillen IC, Rodgers RJ and Perry VEA 2015. Gestational dietary protein is associated with sex specific decrease in blood flow, fetal heart growth and post-natal blood pressure of progeny. PLoS One 10, e0125694.

Hopkins D 1989. Reliability of three sites for measuring fat depth on the beef carcass. Australian Journal of Experimental Agriculture 29, 165-168.

Johnson E 1994. Comparison of the prediction of carcass components using fat thickness measurements in heifers and steers. Australian Journal of Experimental Agriculture 34, 435-438.

Klagsbrun M and D'Amore PA 1991. Regulators of angiogenesis. Annual Review of Physiology 53, 217-239.

Liu X, Wang J, Li R, Yang X, Sun Q, Albrecht E and Zhao R 2011. Maternal dietary protein affects transcriptional regulation of myostatin gene distinctively at weaning and finishing stages in skeletal muscle of Meishan pigs. Epigenetics 6 , 899-907.

Long NM, Vonnahme KA, Hess BW, Nathanielsz PW and Ford SP 2009. Effects of early gestational undernutrition on fetal growth, organ development, and placentomal composition in the bovine. Journal of Animal Science 87, 1950-1959.

Lund-Larsen TR, Sundby A, Kruse V and Velle W 1977. Relation between growth rate, serum somatomedin and plasma testosterone in young bulls. Journal of Animal Science 44, 189-194.

Martin JL, Vonnahme KA, Adams DC, Lardy GP and Funston RN 2007. Effects of dam nutrition on growth and reproductive performance of heifer calves. Journal of Animal Science 85, 841-847.

Micke GC, Sullivan TM, Gatford KL, Owens JA and Perry VE 2010a. Nutrient intake in the bovine during early and mid-gestation causes sex-specific changes in progeny plasma IGF-I, liveweight, height and carcass traits. Animal Reproduction Science 121, 208-217.

Micke GC, Sullivan TM, Kennaway DJ, Hernandez-Medrano J and Perry VEA 2015. Maternal endocrine adaptation throughout pregnancy to nutrient manipulation: consequences for sexually dimorphic programming of thyroid hormones and development of their progeny. Theriogenology 83, 604-615.

Micke GC, Sullivan TM, McMillen IC, Gentili S and Perry VEA 2011a. Heifer nutrient intake during early- and mid-gestation programs adult offspring adiposity and mRNA expression of growth-related genes in adipose depots. Reproduction 141, 697-706.

Micke GC, Sullivan TM, McMillen IC, Gentili S and Perry VEA 2011b. Protein intake during gestation affects postnatal bovine skeletal muscle growth and relative expression of IGF1, IGF1R, IGF2 and IGF2R. Molecular and Cellular Endocrinology 332, 234-241.

Micke GC, Sullivan TM, Rolls PJ, Hasell B, Greer RM, Norman ST and Perry VEA 2010c. Dystocia in 3-year-old beef heifers; relationship to maternal nutrient intake during early- and mid-gestation, pelvic area and hormonal indicators of placental function. Animal Reproduction Science 118, 163-170.

Micke GC, Sullivan TM, Soares Magalhaes RJ, Rolls PJ, Norman ST and Perry VEA 2010b. Heifer nutrition during early- and mid-pregnancy alters fetal growth trajectory and birth weight. Animal Reproduction Science 117, 1-10.

Norman MJT 1963. The pattern of dry matter and nutrient content changes in native pastures at Katherine, N.T. Australian Journal of Experimental Agriculture 3, 119-124.

Oksbjerg N, Gondret F and Vestergaard M 2004. Basic principles of muscle development and growth in meat-producing mammals as affected by the insulin-like growth factor (IGF) system. Domestic Animal Endocrinology 27, 219-240.

Oliver MH, Harding JE, Breier BH and Gluckman PD 1996. Fetal insulin-like growth factor (IGF)-I and IGF-II are regulated differently by glucose or insulin in the sheep fetus. Reproduction, Fertility and Development 8, 167-172.

Perry VEA, Norman ST, Daniel RCW, Owens PC, Grant P and Doogan VJ 2002. Insulin-like growth factor levels during pregnancy in the cow are affected by protein supplementation in the maternal diet. Animal Reproduction Science $72,1-10$. 
Perry VEA, Norman ST, Owen JA, Daniel RCW and Phillips N 1999. Low dietary protein during early pregnancy alters bovine placental development. Animal Reproduction Science 55, 13-21.

Quigley SP, Kleemann DO, Kakar MA, Owens JA, Nattrass GS, Maddocks S and Walker SK 2005. Myogenesis in sheep is altered by maternal feed intake during the peri-conceptal period. Animal Reproduction Science 87, 241-251.

Reynolds LP and Redmer DA 1995. Utero-placental vascular development and placental function. Journal of Animal Science 73, 1839-1851.

Robelin J, Picard B, Listrat A, Jurie C, Barboiron C, Pons F and Geay Y 1993. Myosin expression in semitendinosus muscle during fetal development of cattle: immunocytochemical and electrophoretic analyses. Reproduction, Nutrition, Development 33, 25-41.

Roberts CT, Sohlstrom A, Kind KL, Earl RA, Khong TY, Robinson JS, Owens PC and Owens JA 2001. Maternal food restriction reduces the exchange surface area and increases the barrier thickness of the placenta in the guinea-pig. Placenta 22, 177-185.

Shimada A, Nakano H, Takahashi T, Imai K and Hashizume K 2001. Isolation and characterization of a bovine blastocyst-derived trophoblastic cell line, BT-1: development of a culture system in the absence of feeder cell. Placenta 22, 652-662.

Sullivan T, Micke G, Perkins N, Martin G, Wallace C, Gatford K, Owens J and Perry V 2009a. Dietary protein during gestation affects maternal IGF, IGFBP, leptin concentrations, and fetal growth in heifers. Journal of Animal Science 87, 3304-3316.

Sullivan TM, Micke GC, Magalhaes RS, Phillips NJ and Perry VEA 2009b. Dietary protein during gestation affects placental development in heifers. Theriogenology 72, 427-438.

Sullivan TM, Micke GC, Magalhaes RS, Martin GB, Wallace CR, Green JA and Perry VEA 2009c. Dietary protein during gestation affects circulating indicators of placental function and fetal development in heifers. Placenta 30, 348-354.
Summers AF, Blair AD and Funston RN 2015. Impact of supplemental protein source offered to primiparous heifers during gestation on II. Progeny performance and carcass characteristics. Journal of Animal Science 93, 1871-1880.

Symonds ME, Pope M, Sharkey D and Budge H 2012. Adipose tissue and fetal programming. Diabetologia 55, 1597-1606.

Symonds ME, Pearce S, Bispham J, Gardner D and Stephenson T 2004. Timing of nutrient restriction and programming of fetal adipose tissue development. Proceedings of the Nutrition Society 63, 397-403.

Talbot NC, Caperna TJ, Edwards JL, Garrett W, Wells KD and Ealy AD 2000. Bovine blastocyst-derived trophectoderm and endoderm cell cultures: interferon tau and transferrin expression as respective in vitro markers. Biology of Reproduction 62, 235-247.

Tong JF, Yan X, Zhu MJ, Ford SP, Nathanielsz PW and Du M 2009. Maternal obesity downregulates myogenesis and \{beta\}-catenin signaling in fetal skeletal muscle. American Journal of Physiology 296, E917-E924.

Vonnahme KA, Zhu MJ, Borowicz PP, Geary TW, Hess BW, Reynolds LP, Caton JS, Means WJ and Ford SP 2007. Effect of early gestational undernutrition on angiogenic factor expression and vascularity in the bovine placentome. Journal of Animal Science 85, 2464-2472.

Weibel ER, Kistler GS and Scherle WF 1966. Practical stereological methods for morphometric cytology. The Journal of Cell Biology 30, 23-38.

Wooding FBP and Beckers JF 1987. Trinucleate cells and the ultrastructural localisation of bovine placental lactogen. Cell and Tissue Research 247, 667-673.

Zhu MJ, Du M, Hess BW, Means WJ, Nathanielsz PW and Ford SP 2007. Maternal nutrient restriction upregulates growth signalling pathways in the cotyledonary artery of cow placentomes. Placenta 28, 361-368. 